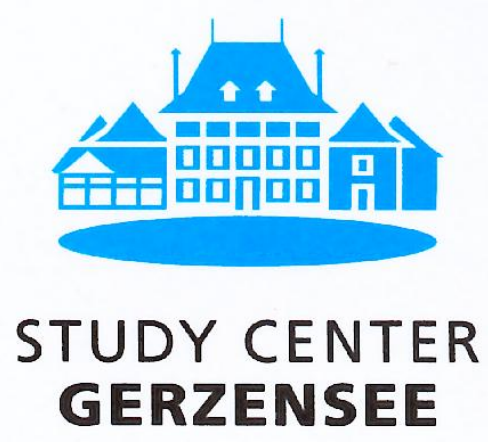

Starving the Beast?

Intra-Generational Conflict and Balanced Budget Rules

\author{
Dirk Niepelt
}

Working Paper 05.04

This discussion paper series represents research work-in-progress and is distributed with the intention to foster discussion. The views herein solely represent those of the authors. No research paper in this series implies agreement by the Study Center Gerzensee and the Swiss National Bank, nor does it imply the policy views, nor potential policy of those institutions. 


\title{
Starving the Beast? Intra-Generational Conflict and Balanced Budget Rules*
}

\author{
Dirk Niepelt \\ Institute for International Economic Studies, Stockholm University \\ and \\ Study Center Gerzensee ${ }^{\dagger}$
}

October 5, 2005

\begin{abstract}
A balanced budget requirement does not only prevent fiscal policy makers from smoothing tax distortions but also affects their preferred choice of government spending. The paper analyzes the conditions under which groups opposed to government spending might want to implement a balanced budget requirement in order to induce the government to spend less. It shows that relaxing a balanced budget requirement need not be associated with higher government spending.
\end{abstract}

JEL Codes: E62, H62.

Keywords: Balanced budget; intra-generational conflict; government spending.

\section{Introduction}

Recent years have witnessed an increased interest in institutional constraints on fiscal policy makers, in particular balanced budget requirements. The theoretical interest in such requirements has in several countries been accompanied by growing political support. In the United States, for example, where weak forms of balanced budget rules are implemented in most states ${ }^{1}$, a similar rule has repeatedly been suggested for the federal government. In Europe, the "close to balance" imperative in the European Union's "Stability and Growth Pact" aims in the same direction.

By preventing a government from shifting tax collections over time, a balanced budget requirement necessarily goes against the interest of a time-consistent government and, to the extent that the government is benevolent, society at large. However, as frequently pointed out, a balanced budget requirement might still play a useful role if it helps avoid that policy makers pursue third-best policies ${ }^{2}$ or shift tax collections in an undesirable fashion across or within

\footnotetext{
${ }^{*}$ I thank the editor, two anonymous referees, Daron Acemoglu, Olivier Blanchard, Ricardo Caballero, Nicola Gennaioli, Torsten Persson, and seminar participants for helpful comments. Editorial assistance by Christina Lönnblad is gratefully acknowledged.

${ }^{\dagger}$ P.O. Box 21, CH-3115 Gerzensee, Switzerland. E-mail: dirk.niepelt@iies.su.se

${ }^{1}$ Cf. Poterba (1994) or Bohn and Inman (1996).

${ }^{2}$ Tabellini and Alesina (1990), Alesina and Drazen (1991), Chari and Cole (1993), and Persson and Tabellini (1999) present models where a balanced budget requirement helps overcome third-best policy outcomes due to common-pool problems.
} 
cohorts. $^{3}$

The requirement to balance the budget does not only affect the timing and welfare cost of tax collections, but also the government's choice of other policy instruments. In particular, it is often argued that restrictions on the government's ability to smooth tax distortions and thus, to raise revenue relatively cheaply, might reduce government spending. ${ }^{4}$ According to this view, groups opposed to government spending might want to implement a balanced budget requirement in order to "starve the beast." 5

This paper asks whether it is indeed possible that intra-generational conflict about the preferred level of government spending can lead certain groups in the population to favor a balanced budget requirement. It finds that the answer to this question does not only depend, as might be expected, on the severity of tax distortions under a balanced budget and the extent of conflict between different groups, but also on whether it is actually the case that more pronounced tax smoothing goes hand in hand with higher government spending. This latter condition need not automatically be satisfied, as shown by the paper.

Section 2 presents the model. Section 3 analyzes the effects of a balanced budget requirement on the allocation, in particular the government's choice of spending, and the welfare of different groups in society. Section 4 briefly discusses extensions and concludes.

\section{The Model}

The economy is closed and deterministic. ${ }^{6}$ It is inhabited by a government and a continuum of households of measure one. Households and the government live from period 0 to period $T .^{7}$ Households value sequences of consumption and leisure according to the time-separable utility measure $U(c, x) \equiv \sum_{t=0}^{T} \beta^{t} u\left(c_{t}, x_{t}\right)$, where $c_{t}$ and $x_{t}$ denote consumption and leisure at time $t$, respectively, the felicity function $u(\cdot)$ satisfies standard regularity conditions, and $\beta \in$ $(0,1)$ denotes the time discount factor. Households also value the level of "general government activity", denoted by $g$, but to different degrees. A fraction $\eta$ of the consumers $(0 \leq \eta \leq 1)-$ call them " $a$-types" - has a relatively strong preference for $g$, described by the utility measure $\xi^{a} f(g)$ with $\xi^{a}>0$ and $f(\cdot)$ being strictly increasing and concave. The remaining fraction of the population - call them "b-types" - has a weaker preference for general government activity, described by the measure $\xi^{b} f(g)$ with $\xi^{a}>\xi^{b} \geq 0$. As in Lucas and Stokey (1983), each household is endowed with one unit of time per period. Production is linear in labor, with productivity given by $w_{t}$.

\footnotetext{
${ }^{3}$ For analyses of the inter-generational wealth effects of budget policy, see Diamond (1965), Barro (1974), Blanchard (1985), and Auerbach, Gokhale and Kotlikoff (1991); for an analysis of the intra-generational wealth effects, see Niepelt (2004).

${ }^{4}$ Blinder and Holtz-Eakin (1984) report that "Respondents divided almost evenly among three general arguments in favor [of balancing the budget]: ... [T] hat balancing the budget is a good way to cut wasteful government programs" (p. 147). Arguments made in the political debate in many countries appear to conform with this view. Buchanan and Wagner (1977, p. 178) emphasize a different effect of balanced budget rules: "The rule will have the effect of bringing the real costs of public outlays to the awareness of decision makers; it will tend to dispel the illusory 'something for nothing' aspects of fiscal choice." Empirically, there is a clearly identified relationship between budgetary institutions and the level of government spending, specifically investment outlays (Poterba, 1994; Peletier, Dur and Swank, 1999).

${ }^{5}$ Krusell, Quadrini and Ríos-Rull (1996) examine a related mechanism. In their paper, higher distortions associated with income rather than consumption taxes depress government transfers.

${ }^{6}$ The extension to a stochastic environment is immediate.

${ }^{7}$ The arguments are not affected if $T$ is replaced by $\infty$ and the following conditions are modified accordingly.
} 
The government's total resource requirement in period $t, g_{t}$, consists of two parts: General government activity, $g$, which is chosen by the government, and an exogenous spending requirement, $g_{e t}$ :

$$
g_{t}=g+g_{\text {et }} \text { for all } t .
$$

The time-varying exogenous spending component represents expenditures that are incurred even by a "minimalist" government providing, e.g., national defense, disaster relief, or elementary social and unemployment insurance. The endogenous spending component, in contrast, represents government expenditures that go beyond the bare minimum, for public transportation or schooling say. Constancy of $g$ reflects the notion that the size of government cannot be changed from year to year. ${ }^{8}$ Total spending is financed by proportional labor-income taxes and government deficits.

Households behave competitively. They take the sequence of prices of the consumption good, $\left\{p_{t}\right\}_{t=0}^{T}$, and tax rates, $\left\{\tau_{t}\right\}_{t=0}^{T}$, as given and choose consumption, leisure, and government debt holdings in order to maximize utility. Since general government activity additively enters household preferences, all households solve the same program, ${ }^{9}$

$$
\max _{\left\{c_{t}, x_{t}\right\}_{t=0}^{T}} \sum_{t=0}^{T} \beta^{t} u\left(c_{t}, x_{t}\right) \text { s.t. } \sum_{t=0}^{T} p_{t}\left[\left(1-\tau_{t}\right) w_{t}\left(1-x_{t}\right)-c_{t}\right]=0,
$$

and thus choose the same consumption bundles in equilibrium.

The first-order conditions of the households' program define consumption and leisure as functions of productivity, tax, and price sequences. Substituting out prices and tax rates allows to reduce these first-order conditions to a single implementability constraint of the form

$$
\sum_{t=0}^{T} \beta^{t}\left[c_{t} u_{c}\left(c_{t}, x_{t}\right)-\left(1-x_{t}\right) u_{x}\left(c_{t}, x_{t}\right)\right]=0 .
$$

This implementability constraint summarizes all conditions imposed by household optimization. In the following, I will use this implementability constraint rather than households' first-order conditions involving taxes and prices to characterize the equilibrium. Accordingly, I will formulate the government's optimization program without reference to the actual policy instruments $\tau$ and $p$, but directly in its "primal" form. ${ }^{10}$

A competitive equilibrium in this economy consists of sequences for consumption and leisure, and a level of general government activity satisfying the implementability constraint, the economy's resource constraints,

$$
\begin{array}{r}
w_{t}-g_{t}=c_{t}+w_{t} x_{t} \text { for all } t, \\
0 \leq x_{t} \leq 1 \text { for all } t,
\end{array}
$$

and, by implication, the government's budget constraint. ${ }^{11}$ Under a balanced budget requirement, the government must also balance its budget in each period. Equivalently, the government

\footnotetext{
${ }^{8}$ The results do not depend on the assumption that endogenous government spending is constant over time. For example, one could assume instead that endogenous government spending varies over time but its level is affected by the choice of $g$. Allowing the government to choose a different level of endogenous spending in each period would shift the focus of the paper away from the link between a balanced budget rule and the size of government.

${ }^{9}$ For simplicity, I assume that no debt is outstanding at the beginning of period 0 .

${ }^{10}$ See Lucas and Stokey (1983) for a discussion of the primal approach to the Ramsey problem.

${ }^{11}$ In equilibrium, a budget deficit is matched by savings of the private sector. The government's intertemporal budget constraint is therefore satisfied whenever the households' budget constraints (and thus, the implementability constraint) and the resource constraints are satisfied.
} 
must choose an allocation equalizing households' after-tax labor incomes and consumption in each period, $c_{t}=w_{t}\left(1-\tau_{t}\right)\left(1-x_{t}\right)$ for all $t$. In its primal form, this zero-savings or budget-balance condition can be expressed as

$$
c_{t} u_{c}\left(c_{t}, x_{t}\right)-\left(1-x_{t}\right) u_{x}\left(c_{t}, x_{t}\right)=0 \text { for all } t .
$$

A competitive equilibrium subject to no balanced budget requirement therefore satisfies (1) and (2), while a competitive equilibrium subject to a balanced budget requirement satisfies (2) and (3). Throughout the analysis, I assume equilibria to be interior and government spending to be feasible, i.e., there exists an $\epsilon>0$ such that $g \leq \epsilon$ implies $w_{t}-g_{t}>0$ for all $t$.

The government's objective function is given by a weighted average of household utilities where $\theta^{i}, i=a, b$, denotes the per-capita welfare weight attached to group $i$. This function can be interpreted as the objective of a utilitarian social planner (a Benthamite planner if $\theta^{a}=\theta^{b}$ ). Alternatively, it provides an approximation of the political decision-making process, for example, if the government maximizes the welfare of one type subject to a reservation utility requirement for the other type ${ }^{12}$, the median voter is decisive ${ }^{13}$, or parties compete in a probabilistic-voting environment. The government's program is thus to

$$
\begin{array}{cl}
\max _{g,\left\{c_{t}, x_{t}\right\}_{t=0}^{T}} & f(g) \frac{\theta^{a} \eta \xi^{a}+\theta^{b}(1-\eta) \xi^{b}}{\theta^{a} \eta+\theta^{b}(1-\eta)}+\sum_{t=0}^{T} \beta^{t} u\left(c_{t}, x_{t}\right) \\
\text { s.t. } & \text { (2) and } \\
& \text { (3) or (1), }
\end{array}
$$

depending on whether a balanced budget requirement is in place. ${ }^{14}$

Suppose that a balanced budget rule is introduced in this economy. The requirement to finance government spending out of contemporary tax revenues reduces the degrees of freedom in the maximization problem of the government to one. (Once $g$ is chosen, all tax rates or, in primal form, equilibrium quantities follow directly from the balanced budget constraint.) The value of the government's problem is therefore weakly lower than without a balanced budget requirement. Why then would a group of households have an interest in a balanced budget requirement? Several conditions must be satisfied:

First, the group in question and the government must disagree about which policy should be implemented. Only then does it make sense for the interest group to support constraints on the government's choice variables. In the setup considered here, where the two types prefer different fiscal policies, this condition is met as soon as the government places strictly positive weight on the welfare of each type. Not only must the government and the interest group disagree about the preferred policy, but the welfare of the interest group under the constrained policy must be higher than under the unconstrained policy.

Second, a balanced budget requirement must be enacted on a higher legislative level than the budget itself to truly represent a constraint to the government. Following the literature

\footnotetext{
${ }^{12}$ Denote welfare of type $i$ by $U^{i}$. The government's problem, $P$ say, is to maximize the objective function $\theta^{a} \eta U^{a}+\theta^{b}(1-\eta) U^{b}$ for some positive weights $\theta^{a}$ and $\theta^{b}$, subject to resource and implementability constraints. Let $U^{a \star}$ and $U^{b \star}$ be the welfare levels and $A$ the allocation solving $P$. Then, $U^{a \star}, U^{b \star}$, and $A$ also solve the problem of maximizing $U^{a}$, subject to the same constraints and the requirement that $U^{b} \geq U^{b \star}$.

${ }^{13}$ For $\eta>0.5$, the median voter setup implies $\theta^{b}=0$ and vice versa.

${ }^{14} \mathrm{I}$ assume that the government is able to commit to the ex-ante optimal policy. An extension of the argument in Lucas and Stokey (1983) shows that the ex-ante optimal policy is time-consistent if the government can commit to honoring its debt and has access to a wide range of maturities.
} 
(e.g., Alesina and Perotti, 1995; Alesina and Perotti, 1996; Poterba and von Hagen, 1999), I assume that this realistic assumption is satisfied. (Any theory arguing that a balanced budget requirement plays any role must make this assumption.) However, this triggers the question of what the political power constellation must be like for restrictions to be enacted at the constitutional level which constrain the behavior at the legislative level. One possible explanation follows the argument of Persson and Svensson (1989) in emphasizing an anticipated change in the distribution of power. ${ }^{15}$ Imagine that the ruling party commands a broad majority of the votes in the legislative branch. This majority allows the party to change the constitution. Furthermore, imagine that the party expects to lose this broad majority in the upcoming election and to share power with other parties in a coalition government. If the party represents the interests of households in favor of constraining the subsequent government, it might want to enact a balanced budget requirement.

Finally, there must only be a few budgetary institutions available that are sufficiently simple and transparent to be practicable and credible (cf. Buchanan and Wagner, 1977, p. 176). If more than just a few such institutions were available, an interest group would try to enact a different, more efficient constraint than a balanced budget rule. Throughout the paper, I assume a balanced budget requirement to be the only available constitutional constraint.

\section{Effects of a Balanced Budget Requirement}

To shed further light on the first condition discussed above-higher welfare for the interest group under the constrained than under the unconstrained policy - it is helpful to impose more structure on the problem. I therefore assume that household preferences are logarithmic, $u\left(c_{t}, x_{t}\right) \equiv \ln \left(c_{t}\right)+\gamma \ln \left(x_{t}\right), f(g) \equiv \ln (g)$. Under this functional form assumption, the implementability constraints (1) and (3) reduce to

$$
\frac{1+\gamma}{\gamma} \sum_{t=0}^{T} \beta^{t}=\sum_{t=0}^{T} \beta^{t} \frac{1}{x_{t}}
$$

and

$$
x_{t}=\frac{\gamma}{1+\gamma} \text { for all } t
$$

respectively. The government program therefore reads

$$
\begin{array}{cl}
\max _{g,\left\{c_{t}, x_{t}\right\}_{t=0}^{T}} & \ln (g) \frac{\theta^{a} \eta \xi^{a}+\theta^{b}(1-\eta) \xi^{b}}{\theta^{a} \eta+\theta^{b}(1-\eta)}+\sum_{t=0}^{T} \beta^{t}\left(\ln \left(c_{t}\right)+\gamma \ln \left(x_{t}\right)\right) \\
\text { s.t. } & \text { (2) and } \\
& \text { (5) or (4), }
\end{array}
$$

depending on whether a balanced budget requirement is in place.

Using (2), $c_{t}$ can be eliminated from the government's program, leaving $x_{t}, t=0, \ldots, T$, and $g$ as the sole endogenous variables. Under a balanced budget requirement, condition (5)

\footnotetext{
${ }^{15}$ Persson and Svensson (1989) analyze how a budget deficit or surplus by one government influences the spending decision of the subsequent one. They show that a "conservative" government might run a deficit to induce a subsequent "liberal" government (favoring higher government expenditure) to spend less. de Figueiredo Jr. (2003) discusses related empirical evidence in the context of state legislatures granting item vetoes to the governor.
} 
pins down $x_{t}, t=0, \ldots, T$, reflecting the fact that the government has no ability to smooth tax distortions over time. Without a balanced budget requirement, the equilibrium sequence for leisure is only constrained by (4) since the government does have the ability to smooth tax distortions. Differentiating the government's objective function with respect to $x_{t}$ then yields the first-order condition

$$
\beta^{t}\left[\left(\frac{\gamma}{x_{t}}-\frac{w_{t}}{w_{t}\left(1-x_{t}\right)-g_{t}}\right)-\left(\frac{\gamma}{x_{0}}-\frac{w_{0}}{w_{0}\left(1-x_{0}\right)-g_{0}}\right)\left(\frac{x_{0}}{x_{t}}\right)^{2}\right]=0, t=1, \ldots, T,
$$

according to which the optimal debt policy equalizes deadweight losses of taxation over time. These deadweight losses are reflected in wedges between the marginal utility of leisure and the productivity-weighted marginal utility of consumption. The period- $t$ wedge, for example, is given by

$$
u_{x}\left(c_{t}, x_{t}\right)-w_{t} u_{c}\left(c_{t}, x_{t}\right)=u_{x}\left(c_{t}, x_{t}\right)-\frac{u_{x}\left(c_{t}, x_{t}\right)}{1-\tau_{t}}=\frac{-\tau_{t}}{1-\tau_{t}} u_{x}\left(c_{t}, x_{t}\right)
$$

and therefore equal to zero, of course, if no taxes are levied.

Differentiating the government's objective function with respect to $g$ yields the first-order condition

$$
\frac{\theta^{a} \eta \xi^{a}+\theta^{b}(1-\eta) \xi^{b}}{\theta^{a} \eta+\theta^{b}(1-\eta)} \frac{1}{g}-\sum_{t=0}^{T} \beta^{t} \frac{1}{w_{t}\left(1-x_{t}\right)-g-g_{e t}}=0
$$

which holds independently of whether a balanced budget requirement is in place.

Two results prove useful for the following discussion. The first characterizes the tax smoothing policy around the balanced budget allocation. It follows from evaluating (6) at $x_{t}=\gamma /(1+\gamma)$ for all $t$ :

Lemma 1. Suppose that $w_{t}>g_{t}(1+\gamma)$ for all $t$ such that a balanced budget policy is implementable. Consider a marginal increase in $x_{t}, t=1, \ldots, T$, around the balanced budget allocation. The welfare effect of this marginal increase, $V_{t}$, is given by

$$
V_{t}=\beta^{t}(1+\gamma)^{2} \frac{w_{t} g_{0}-w_{0} g_{t}}{\left(w_{0}-g_{0}(1+\gamma)\right)\left(w_{t}-g_{t}(1+\gamma)\right)} .
$$

The marginal increase in $x_{t}$ and the corresponding reduction of $x_{0}$ around the balanced budget allocation therefore raise social welfare, $V_{t} \geq 0$, iff

$$
\frac{w_{0}}{w_{0}-g_{0}(1+\gamma)} \geq \frac{w_{t}}{w_{t}-g_{t}(1+\gamma)} \text { or, equivalently, } \frac{g_{0}}{w_{0}} \geq \frac{g_{t}}{w_{t}} \text { or } \tau_{0} \geq \tau_{t} .
$$

The second result follows from totally differentiating (7) with respect to $g$ and $x_{t}$ at the balanced budget allocation (where (4) governs the effect of a marginal change in $x_{t}$ on $x_{0}$ ):

Lemma 2. Suppose that $w_{t}>g_{t}(1+\gamma)$ for all $t$ such that a balanced budget policy is implementable. Consider a marginal increase in $x_{t}, t=1, \ldots, T$, around the balanced budget allocation. The effect of this marginal increase on the level of general government activity, $\Delta_{t}$, is given by

$$
\Delta_{t}=\left.\frac{d g}{d x_{t}}\right|_{\mathrm{BB}}=\frac{\beta^{t}(1+\gamma)^{2}\left(\frac{w_{0}}{\left(w_{0}-g_{0}(1+\gamma)\right)^{2}}-\frac{w_{t}}{\left(w_{t}-g_{t}(1+\gamma)\right)^{2}}\right)}{\frac{\Xi}{g^{2}}+(1+\gamma)^{2}\left(\frac{1}{\left(w_{0}-g_{0}(1+\gamma)\right)^{2}}+\frac{\beta^{t}}{\left(w_{t}-g_{t}(1+\gamma)\right)^{2}}\right)},
$$


where $\Xi \equiv \frac{\theta^{a} \eta \xi^{a}+\theta^{b}(1-\eta) \xi^{b}}{\theta^{a} \eta+\theta^{b}(1-\eta)}$ and $g$ is evaluated at its optimal value under the balanced budget constraint, given by (5) and (7). The marginal increase in $x_{t}$ and the corresponding reduction of $x_{0}$ around the balanced budget allocation therefore raise $g$ iff

$$
\frac{w_{0}}{\left(w_{0}-g_{0}(1+\gamma)\right)^{2}} \geq \frac{w_{t}}{\left(w_{t}-g_{t}(1+\gamma)\right)^{2}} .
$$

A comparison of the inequality conditions stated in the two Lemmas shows that $V_{t} \geq 0$ does not necessarily imply $\Delta_{t} \geq 0$. A small policy change around the balanced budget allocation towards tax smoothing need therefore not imply an increase in government spending. Intuitively, a marginal increase in $x_{t}$ and a corresponding reduction of $x_{0}$ imply stronger tax smoothing if they tend to equalize tax distortions in the two periods. Due to identical marginal utilities of leisure around the balanced budget allocation (see condition (5)), this requires that the marginal increase in $x_{t}$ and the corresponding reduction of $x_{0}$ tend to equalize the productivity-weighted marginal utility of consumption in period 0 and period $t$. This is the case if the former exceeds the latter, corresponding to the condition given in Lemma 1. The effect of the policy change on tax distortions thus depends on marginal utilities.

The effect of the policy change on the level of general government activity, in contrast, depends on changes in marginal utilities, as can be seen from the condition stated in Lemma 2 . A move towards tax smoothing increases $g$, if it reduces the opportunity cost of $g$. (The marginal benefit of $g$ is unaffected by the policy change, due to separability.) This opportunity cost, reflected by the right-hand side of equation (7), is given by the present discounted value of marginal utility losses due to less resources available for consumption. The effect of more tax smoothing on this cost depends on the effect on average marginal utilities of consumption and thus, the derivatives of marginal utility. The cost of $g$ may therefore rise even if the policy change reduces tax distortions.

Whether the signs of $V_{t}$ and $\Delta_{t}$ differ depends on the factors influencing marginal utilities, in particular labor productivity and exogenous government spending. In general, all sign combinations may arise. The potential for differences between the signs of $V_{t}$ and $\Delta_{t}$ disappears, however, if labor productivity does not vary between periods 0 and $t$. This can be directly seen from a comparison of the conditions stated in Lemmas 1 and 2. Therefore, we have the following result:

Lemma 3. Suppose that $w_{t}>g_{t}(1+\gamma)$ for all $t$ such that a balanced budget policy is implementable. Consider a marginal increase in $x_{t}, t=1, \ldots, T$, around the balanced budget allocation. If $w_{t}=w_{0}$, then $\operatorname{sign}\left(V_{t}\right)=\operatorname{sign}\left(\Delta_{t}\right)$, i.e., the marginal increase in $x_{t}$ and the corresponding reduction of $x_{0}$ induce higher $g$ iff they correspond to stronger tax smoothing.

Building on Lemmas 1-3, we can characterize the marginal welfare effects of a relaxation of a balanced budget requirement. This allows us to gain further insight into the conditions under which different groups in society disagree about the desirability of (the relaxation of) a balanced budget requirement.

Relaxing the balanced budget requirement and marginally increasing $x_{t}$ has two effects. First, it amounts to stronger or weaker tax smoothing, with corresponding welfare effects for all groups in society as characterized in Lemma 1. Second, it affects $g$ by the amount characterized in Lemma 2. The change in $g$, in turn, has two welfare effects. On the one hand, it affects the utility from government spending, and on the other hand, it affects the utility from equilibrium consumption. While all groups in society and the government value the latter effect identically, 
they disagree about the valuation of the former if $\theta^{a}, \theta^{b}>0$ and $\xi^{a} \neq \xi^{b}$. Formally, the marginal welfare effects of an increase in $x_{t}$ on $a$-types, $b$-types, and the government are given by

$$
\begin{aligned}
W_{t}^{a} & =V_{t}+\left(\frac{\xi^{a}}{g}-\sum_{t=0}^{T} \beta^{t} \frac{1}{w_{t}\left(1-x_{t}\right)-g-g_{e t}}\right) \Delta_{t}, \\
W_{t}^{b} & =V_{t}+\left(\frac{\xi^{b}}{g}-\sum_{t=0}^{T} \beta^{t} \frac{1}{w_{t}\left(1-x_{t}\right)-g-g_{e t}}\right) \Delta_{t}, \\
W_{t}^{g} & =V_{t}+\left(\frac{\theta^{a} \eta \xi^{a}+\theta^{b}(1-\eta) \xi^{b}}{\theta^{a} \eta+\theta^{b}(1-\eta)} \frac{1}{g}-\sum_{t=0}^{T} \beta^{t} \frac{1}{w_{t}\left(1-x_{t}\right)-g-g_{e t}}\right) \Delta_{t}=V_{t},
\end{aligned}
$$

respectively, where $g$ is evaluated at its optimal value under the balanced budget constraint, given by (5) and (7).

Figures 1-4 display these marginal welfare effects due to an increase in $x_{1}$ as a function of $g_{e 1}$ under the assumption that $T=1$ (corresponding, for example, to a two-period cycle) and $\gamma=0.5, \beta=1, g_{e 0}=0.5, w_{0}=4, \theta^{a}=1, \theta^{b}=1, \eta=.5, \xi^{b}=0$. The parameter values for $w_{1}$ and $\xi^{a}$ differ across the figures.

Figures 1 and 2 display $W_{1}^{a}, W_{1}^{b}, W_{1}^{g}$ and $\Delta_{1}$ under the assumption that labor productivity varies across the two periods $\left(w_{0}=4>w_{1}=3\right)$. In accordance with the findings discussed above, Figure 1 shows that the effect on tax distortions and $g$ need not have the same sign. For example, a rise in $x_{1}$ reduces tax distortions and $g$ if $g_{e 1}$ lies in an interval around 0.2.

Figure 2 exemplifies the effect of a more pronounced disagreement between $a$ - and $b$-types $\left(\xi^{a}=10\right.$ rather than $\xi^{a}=1$ as in Figure 1). The higher level of $\xi^{a}$ implies that the equilibrium level of $g$ under a balanced budget increases. Relaxing the balanced budget requirement implies a further increase of $g$. The welfare implications of higher spending dominate those of lower tax distortions, and the relaxation of a balanced budget requirement therefore mainly has distributive implications.

Figures 3 and 4 display $W_{1}^{a}, W_{1}^{b}, W_{1}^{g}$ and $\Delta_{1}$ under the assumption that labor productivity does not vary across the two periods $\left(w_{0}=w_{1}=4\right)$. In accordance with Lemma 3 , the figures show the effects on tax distortions and $g$ to have the same sign. Relaxing the balanced budget requirement therefore leads the government to smooth tax distortions and raise $g$. As long as the conflict between $a$ - and $b$-types is not very pronounced, as in Figure 3 where $\xi^{a}=1$, all groups in society agree that relaxing the balanced budget constraint is desirable. If, however, the degree of conflict surpasses a threshold, as assumed for Figure 4 where $\xi^{a}=10$, then $b$-types are opposed to relaxing a balanced budget requirement, because such a step goes hand in hand with significantly higher government spending.

Figure 5 displays the welfare effect for $b$-types, $W_{1}^{b}$, as a function of both $w_{1}$ and $g_{e 1}$ under the maintained assumption that intra-generational conflict with respect to the desirability of government spending is high $\left(\xi^{a}=10\right)$. All other parameter values are the same as in Figures 14. The figure shows that $b$-types are opposed to a marginal rise in $x_{1}$, if $w_{1}$ is relatively large. It is exactly in this parameter region, however, that such a policy change amounts to stronger tax smoothing and thus, the government's preferred policy. Similarly, $b$-types favor a marginal increase in $x_{1}$ around the balanced budget allocation, if $w_{1}$ is relatively small: while such a policy implies higher tax distortions, it induces the government to spend less. For a wide range of combinations of $w_{1}$ and $g_{e 1}$, the government's interests and those of $b$-types are therefore strictly opposed. 
Naturally, disagreement about the desirability of a marginal relaxation of a balanced budget requirement does not imply disagreement about fully relaxing such a requirement. Nevertheless, the above conclusion does not change to any great extent when total rather than marginal welfare effects of relaxing a balanced budget requirement are considered. Solving for the equilibrium allocations with and without balanced budget requirement in the range of parameter values underlying Figure 5, it is found that $b$-types prefer a balanced budget allocation for more than 96 percent of the $\left(w_{1}, g_{e 1}\right)$ combinations displayed in the figure. Moving from the allocation under a balanced budget to the tax-smoothing allocation implemented by the unconstrained government benefits $b$-types only if $w_{1} \approx 4.4$ and $g_{e 1} \approx 0.77$, and even then only slightly, see Figure 6. Otherwise, the benefits of tax smoothing are outweighed by the cost of higher induced government spending.

If the extent of intra-generational conflict is significantly reduced $\left(\xi^{a}=1\right), b$-types prefer the imposition of a balanced budget requirement only in 38 percent of the possible constellations, see Figure 7. Due to the less pronounced disagreement about the preferred level of government spending, the direct benefits of tax smoothing become more important for $b$-types. These direct benefits are particularly strong if $w_{1}$ is relatively small and $g_{e 1}$ is relatively large.

\section{Concluding Remarks}

This paper has examined the notion that groups opposed to government spending might want to implement a balanced budget requirement to "starve the beast", i.e., to induce the government to spend less.

We have found some theoretical support for this notion. Whether groups opposed to government spending indeed support a balanced budget requirement depends on several factors: The severity of tax distortions under a balanced budget; the extent of conflict between different groups; and the link between tax smoothing and the opportunity cost of government spending. This link is non-trivial, implying that more pronounced tax smoothing need not go hand in hand with higher government spending. Nevertheless, quantitative simulations have shown that households opposed to government spending often are in favor of a balanced budget requirement.

Households do not only differ with respect to their preference for government spending, but also along many other dimensions. In particular, they have different levels of productivity and income, which triggers the question of whether productivity differences significantly affect the results of the previous section. To answer this question, it is useful to distinguish between level differences and slope differences between $a$ - and $b$-types' productivity sequences. Derivations deferred to the Appendix show that, if productivity differences only relate to levels, the previous results remain essentially unchanged. Around the balanced budget allocation, labor supply is constant across types, and remains at the same level as before; permanent productivity differences across types are only reflected in corresponding differences in the consumption levels. The marginal conditions analyzed in the paper therefore remain unchanged, except for a scaling of $w_{t}$.

If households do not only differ with respect to their preference for government spending and their average productivity, but also with respect to the time profile of their productivity sequences, a new dimension of intra-generational conflict emerges. In this case, the timing of tax collections does not only affect the level of $g$, but also redistributes wealth between $a$ - and $b$-types. The welfare effects of budget-policy induced redistribution as well as the resolution of the conflicts surrounding budget policy by means of a balanced budget requirement are discussed 
in Niepelt (2004). 


\section{A Productivity-Level Differences}

This Appendix derives the equilibrium conditions of the model under the assumption that productivity of $a$-types is $\alpha$ times as large as the productivity of $b$-types, $w_{t}^{a}=\alpha w_{t}^{b}$ for all $t$. For $\alpha=1$, the main model follows.

Household $i$ 's first-order conditions are given by $\beta^{t} c_{0}^{i} / c_{t}^{i}=p_{t} / p_{0}$ and $w_{t}^{i}\left(1-\tau_{t}\right) / c_{t}^{i}=\gamma / x_{t}^{i}$ for all $t$, as well as the budget constraint. Substituting out prices and tax rates reduces these first-order conditions to the implementability constraints

$$
\begin{gathered}
\sum_{t=0}^{T} \beta^{t}\left(1-\gamma\left(1-x_{t}^{a}\right) / x_{t}^{a}\right)=0 \\
\sum_{t=0}^{T} \beta^{t}\left(1-\gamma\left(1-x_{t}^{b}\right) / x_{t}^{b}\right)=0 \\
\frac{c_{t}^{a}}{c_{t}^{b}}=\frac{c_{0}^{a}}{c_{0}^{b}} \equiv c \text { for all } t \\
\frac{x_{t}^{a} w_{t}^{a}}{x_{t}^{b} w_{t}^{b}}=c \text { for all } t .
\end{gathered}
$$

The first two equations combine the households' budget constraints with the static and dynamic optimality conditions. The third condition captures the restriction that all households face the same prices, and the fourth condition states that the marginal rates of substitution between goods and leisure, adjusted for differences in productivity, are identical across households (because both types of consumers are subject to the same marginal tax rates). Using $w_{t}^{a}=\alpha w_{t}^{b}$ and manipulating these equations yields

$$
\begin{aligned}
\frac{c}{\alpha} \frac{1+\gamma}{\gamma} \sum_{t=0}^{T} \beta^{t} & =\sum_{t=0}^{T} \beta^{t} \frac{1}{x_{t}^{b}}, \\
\frac{1+\gamma}{\gamma} \sum_{t=0}^{T} \beta^{t} & =\sum_{t=0}^{T} \beta^{t} \frac{1}{x_{t}^{b}}, \\
c_{t}^{a} & =c_{t}^{b} c \text { for all } t, \\
x_{t}^{a} & =x_{t}^{b} c / \alpha \text { for all } t,
\end{aligned}
$$

and therefore

$$
\begin{array}{r}
\frac{1+\gamma}{\gamma} \sum_{t=0}^{T} \beta^{t}=\sum_{t=0}^{T} \beta^{t} \frac{1}{x_{t}^{b}}, \\
c_{t}^{a}=c_{t}^{b} \alpha, \quad x_{t}^{a}=x_{t}^{b} \text { for all } t .
\end{array}
$$

The resource constraint reads $(\eta \alpha+1-\eta)\left(1-x_{t}^{b}\right) w_{t}^{b}=g_{t}+(\eta \alpha+1-\eta) c_{t}^{b}$ or

$$
c_{t}^{b}=\frac{(\eta \alpha+1-\eta) w_{t}^{b}\left(1-x_{t}^{b}\right)-g_{t}}{\eta \alpha+1-\eta} \text { for all } t .
$$

Under a balanced budget requirement, the government must also satisfy the condition $(\eta \alpha+1-$ $\eta)\left(1-x_{t}^{b}\right) w_{t} \tau_{t}=g_{t}$. Using the household's intra-temporal first-order condition as well as the 
resource constraint, this balanced budget condition reduces to

$$
x_{t}=\frac{\gamma}{1+\gamma} \text { for all } t
$$

A competitive equilibrium subject to no balanced budget requirement therefore satisfies (8), (9), and (10), while a competitive equilibrium subject to a balanced budget requirement satisfies (9), (10) and (11). Omitting a constant term in the objective function, the government program then reads

$$
\begin{array}{cl}
\max _{g,\left\{c_{t}^{b}, x_{t}^{b}\right\}_{t=0}^{T}} & \ln (g) \frac{\theta^{a} \eta \xi^{a}+\theta^{b}(1-\eta) \xi^{b}}{\theta^{a} \eta+\theta^{b}(1-\eta)}+\sum_{t=0}^{T} \beta^{t}\left(\ln \left(c_{t}^{b}\right)+\gamma \ln \left(x_{t}^{b}\right)\right) \\
\text { s.t. } & (10) \text { and }
\end{array}
$$

$$
\text { (11) or (8), }
$$

depending on whether a balanced budget requirement is in place.

Using (10), $c_{t}^{b}$ can be eliminated from the government's program, leaving $x_{t}^{b}, t=0, \ldots, T$, and $g$ as the sole remaining endogenous variables. Differentiating the government's resulting objective function with respect to $x_{t}^{b}$ and $g$ and letting $z \equiv \eta \alpha+1-\eta$ then yields the first-order conditions

$$
\begin{aligned}
& \left(\frac{\gamma^{b}}{x_{t}^{b}}-\frac{w_{t}^{b} z}{\left(1-x_{t}^{b}\right) w_{t}^{b} z-g_{t}}\right)=\left(\frac{\gamma^{b}}{x_{0}^{b}}-\frac{w_{0}^{b} z}{\left(1-x_{0}^{b}\right) w_{0}^{b} z-g_{0}}\right)\left(\frac{x_{0}^{b}}{x_{t}^{b}}\right)^{2}, t=1, \ldots, T, \\
& \frac{\theta^{a} \eta \xi^{a}+\theta^{b}(1-\eta) \xi^{b}}{\theta^{a} \eta+\theta^{b}(1-\eta)} \frac{1}{g}=\sum_{t=0}^{T} \beta^{t} \frac{1}{z w_{t}^{b}\left(1-x_{t}^{b}\right)-g-g_{e t}} .
\end{aligned}
$$

These conditions are identical to the first-order conditions in the main model, when the productivity sequence is scaled by factor $z$.

\section{References}

Alesina, A. and Drazen, A. (1991), 'Why are stabilizations delayed?', American Economic Review 81(5), 1170-1188.

Alesina, A. and Perotti, R. (1995), 'The political economy of budget deficits', IMF Staff Papers 42(1), 1-31.

Alesina, A. and Perotti, R. (1996), Budget deficits and budget institutions, Working Paper 5556, NBER, Cambridge, Massachusetts.

Auerbach, A. J., Gokhale, J. and Kotlikoff, L. J. (1991), Generational accounts: A meaningful alternative to deficit accounting, in D. Bradford, ed., 'Tax Policy and the Economy', Vol. 5, MIT Press, Cambridge, Massachusetts, pp. 55-110.

Barro, R. J. (1974), 'Are government bonds net wealth?', Journal of Political Economy 82(6), 1095-1117.

Blanchard, O. J. (1985), 'Debt, deficits, and finite horizons', Journal of Political Economy 93(2), 223-247. 
Blinder, A. S. and Holtz-Eakin, D. (1984), 'Public opinion and the balanced budget', American Economic Review 74(2), 144-149.

Bohn, H. and Inman, R. P. (1996), 'Balanced-budget rules and public deficits: Evidence from the U.S. states', Carnegie-Rochester Conference Series on Public Policy 45, 13-76.

Buchanan, J. M. and Wagner, R. E. (1977), Democracy in Deficit: The Political Legacy of Lord Keynes, Academic Press, New York.

Chari, V. V. and Cole, H. (1993), Why are representative democracies fiscally irresponsible?, Research Department Staff Report 163, Federal Reserve Bank of Minneapolis, Minneapolis.

de Figueiredo Jr., R. J. (2003), 'Budget institutions and political insulation: Why states adopt the item veto', Journal of Public Economics 87, 2677-2701.

Diamond, P. A. (1965), 'National debt in a neoclassical growth model', American Economic Review 55(5), 1126-1150.

Krusell, P., Quadrini, V. and Ríos-Rull, J.-V. (1996), 'Are consumption taxes really better than income taxes?', Journal of Monetary Economics 37, 475-503.

Lucas, R. E. and Stokey, N. L. (1983), 'Optimal fiscal and monetary policy in an economy without capital', Journal of Monetary Economics 12(1), 55-93.

Niepelt, D. (2004), 'Tax smoothing versus tax shifting', Review of Economic Dynamics 7(1), 2751.

Peletier, B. D., Dur, R. A. J. and Swank, O. H. (1999), 'Voting on the budget deficit: Comment', American Economic Review 89(5), 1377-1381.

Persson, T. and Svensson, L. E. O. (1989), 'Why a stubborn conservative would run a deficit: Policy with time-inconsistent preferences', Quarterly Journal of Economics 104(2), 325345.

Persson, T. and Tabellini, G. (1999), Political economics and macroeconomic policy, in J. B. Taylor and M. Woodford, eds, 'Handbook of Macroeconomics', Vol. 1C, Elsevier Science, Amsterdam, chapter 22, pp. 1397-1482.

Poterba, J. M. (1994), 'State responses to fiscal crises: The effects of budgetary institutions and politics', Journal of Political Economy 102(4), 799-821.

Poterba, J. M. and von Hagen, J. (1999), Introduction, in J. M. Poterba and J. von Hagen, eds, 'Fiscal Institutions and Fiscal Performance', University of Chicago Press, Chicago, pp. $1-12$.

Tabellini, G. and Alesina, A. (1990), 'Voting on the budget deficit', American Economic Review 80, 37-49. 


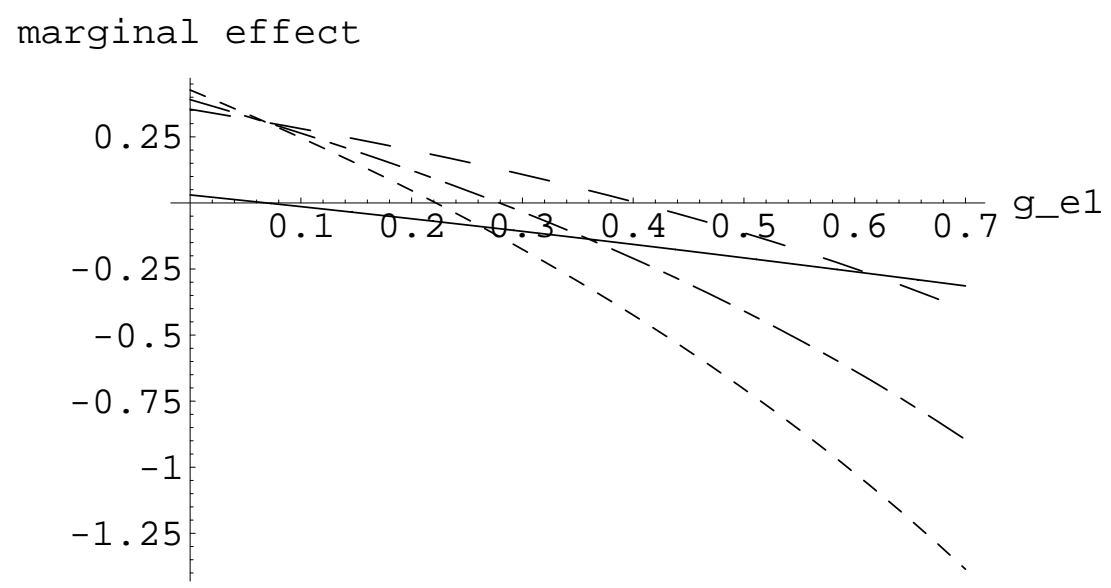

Figure 1: $W_{1}^{a}[\cdots], W_{1}^{g}[\cdot-], W_{1}^{b}[--], \Delta_{1}[-]$. Parameter values: $w_{1}=3, \xi^{a}=1$.

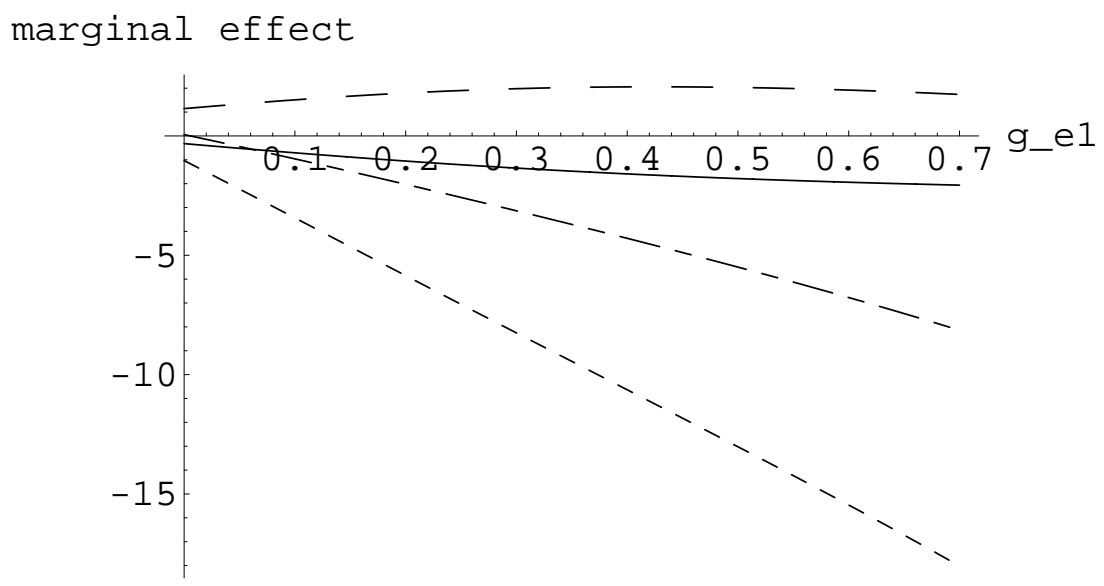

Figure 2: $W_{1}^{a}[\cdots], W_{1}^{g}[\cdot-], W_{1}^{b}[--], \Delta_{1}[-]$. Parameter values: $w_{1}=3, \xi^{a}=10$. 


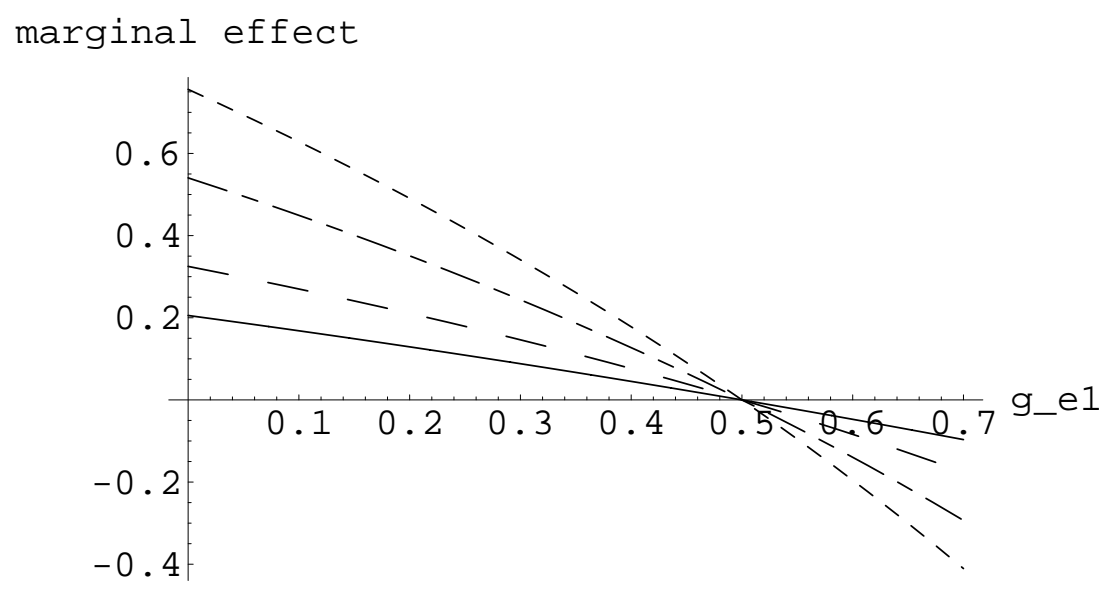

Figure 3: $W_{1}^{a}[\cdots], W_{1}^{g}[\cdot-], W_{1}^{b}[--], \Delta_{1}[-]$. Parameter values: $w_{1}=4, \xi^{a}=1$.

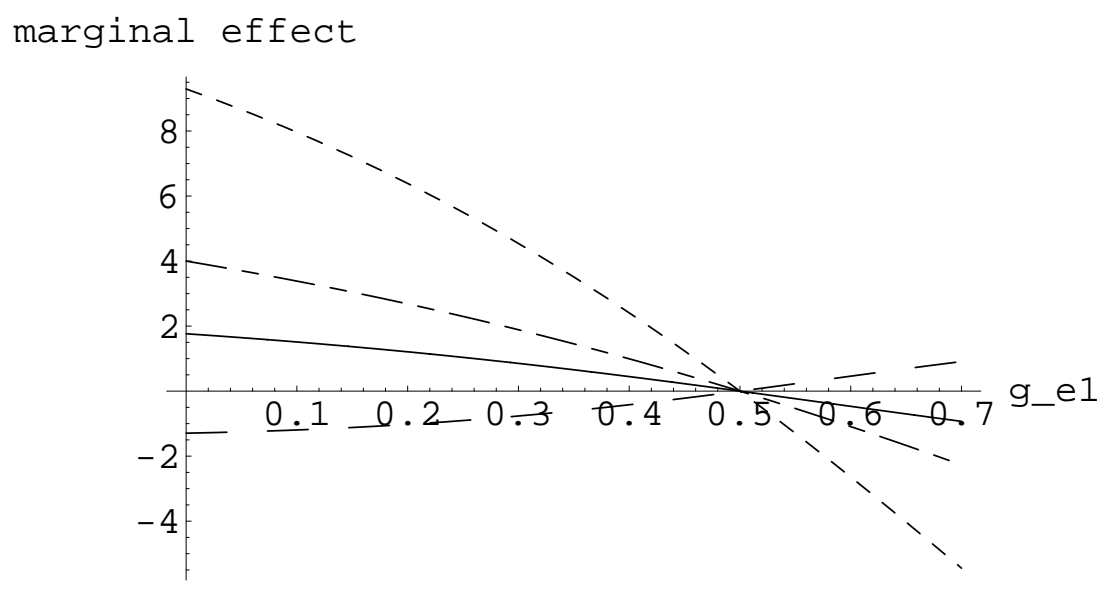

Figure 4: $W_{1}^{a}[\cdots], W_{1}^{g}[\cdot-], W_{1}^{b}[--], \Delta_{1}[-]$. Parameter values: $w_{1}=4, \xi^{a}=10$. 


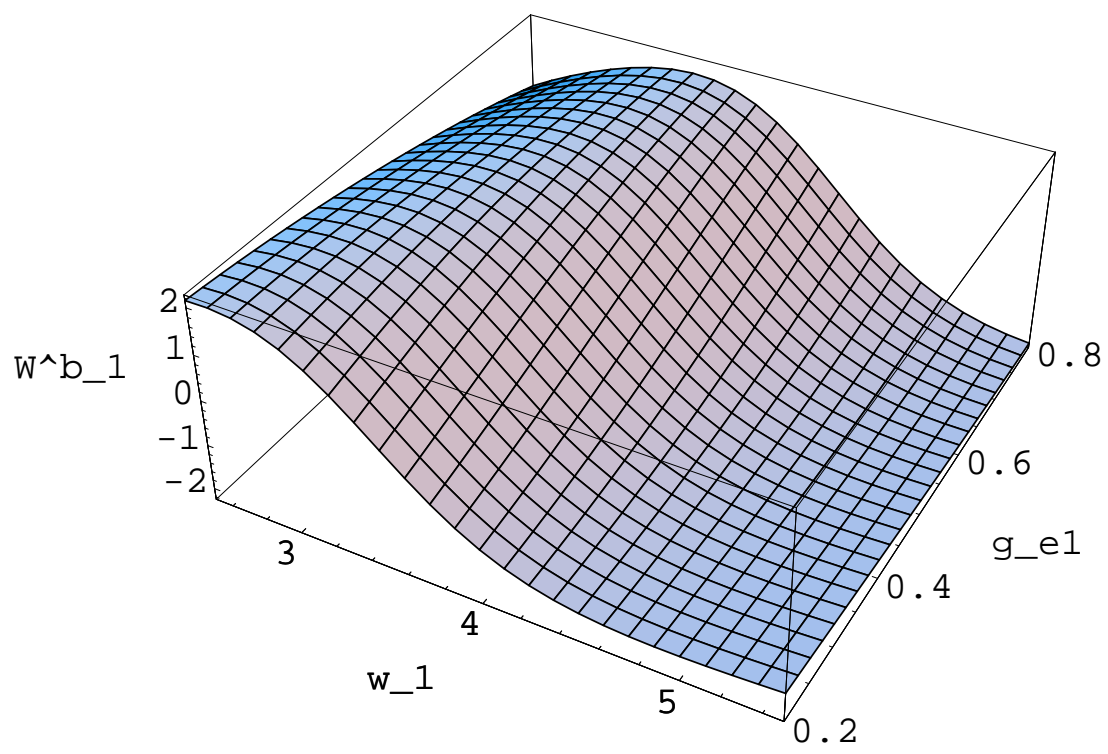

Figure 5: $W_{1}^{b}$. Parameter value: $\xi^{a}=10$.

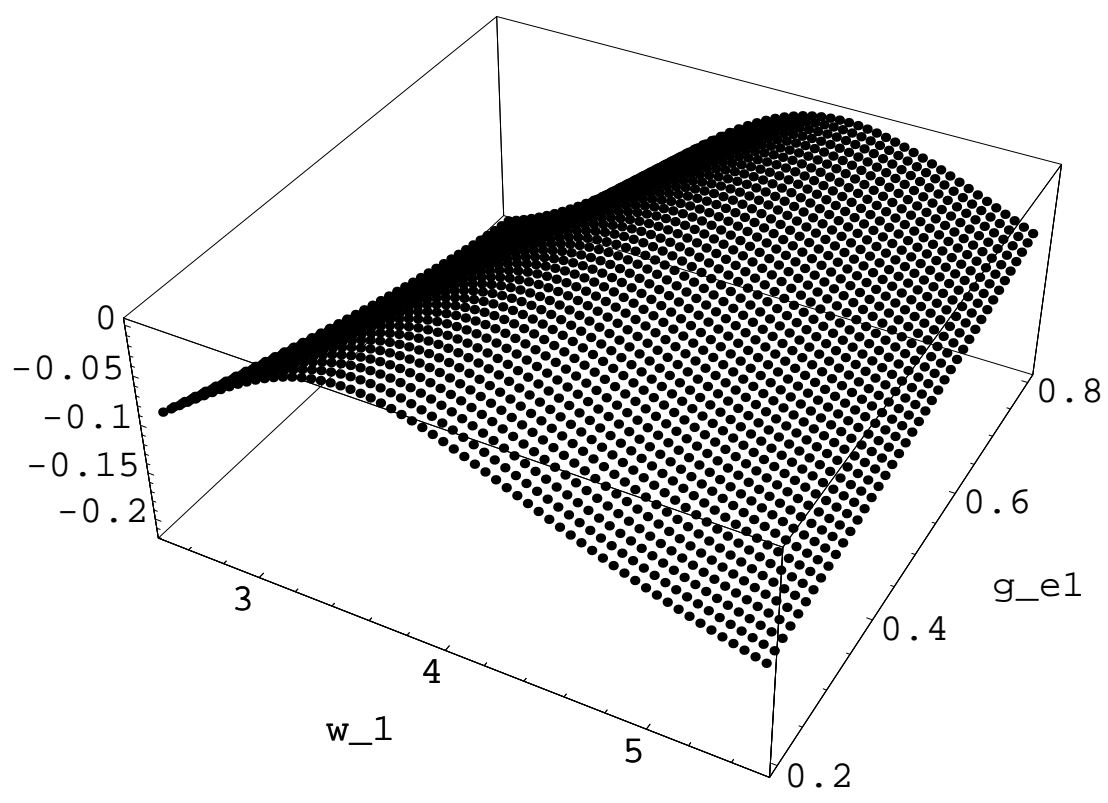

Figure 6: Total welfare effect for $b$-types of moving from balanced budget allocation to tax smoothing allocation. Parameter value: $\xi^{a}=10$. 


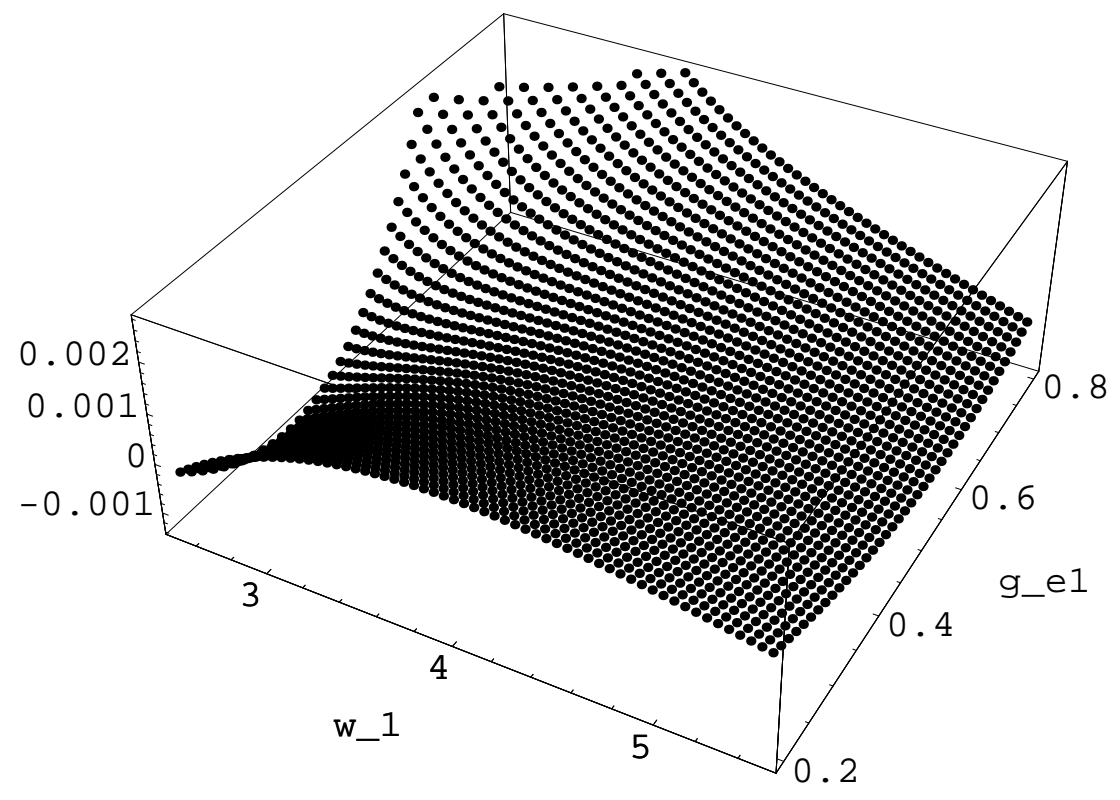

Figure 7: Total welfare effect for $b$-types of moving from balanced budget allocation to tax smoothing allocation. Parameter value: $\xi^{a}=1$. 